\title{
Análise da jornada do cliente e seus pontos de contato em um shopping center popular: o caso do Pop Center de Porto Alegre
}

\author{
Manoela Lawall Radtke - nana_mopi@yahoo.com.br ${ }^{1}$ \\ Cláudio Vinicius Silva Farias - claudio.farias@poa.ifrs.edu.br \\ Lélis Balestrin Espartel - lbespartel@pucrs.br
}

Resumo - Entender e mapear a jornada do cliente no varejo traz implicações acadêmicas relevantes, na medida em que permite uma maior compreensão da experiência do cliente. Gerencialmente, permite identificar pontos de diferenciação e propor ações que gerem maior satisfação aos clientes. $\mathrm{O}$ artigo explora a jornada do cliente do Pop Center, shopping popular de Porto Alegre, no Rio Grande do Sul, identificando os pontos de contato do cliente em suas experiências de compra. A partir de uma survey com clientes, foram identificados os 10 principais pontos de contato do cliente com o shopping envolvendo diferentes momentos da jornada e permitindo a proposição de ações estratégicas para cada um deles.

Palavras-chave: Jornada do cliente. Experiência do consumidor. Shopping popular.

\section{Analysis of customer journey and their touch points in a popular shopping center: the case of the Pop Center in Porto Alegre}

\begin{abstract}
Understanding and mapping the customer journey in retail has relevant academic implications, as it allows a greater understanding of the customer experience. Managerially, it allows identifying points of differentiation and proposing actions that generate greater customer satisfaction. This paper explores the customer journey of the Pop Center, a popular shopping center in Porto Alegre, Rio Grande do Sul, identifying the customer's touch points in their shopping experiences. From a survey with customers, the 10 main touch points between the customer and the shopping mall were identified, involving different moments of the journey and allowing the proposition of strategic actions for each one of them.
\end{abstract}

Keywords: Customer journey; customer experience; popular shopping mall. 


\section{Introdução}

Rápidas mudanças comportamentais, econômicas e culturais da sociedade moderna desafiam constantemente as práticas de mercado. O consumidor se vê, diariamente, circundado por inúmeras opções distintas, o que o faz associar os produtos e serviços expostos e oferecidos e, portanto, compará-los. Por essa razão, marcas e empresas geralmente reconhecem a experiência do cliente como um componente importante para sustentar uma vantagem competitiva (BECKER; JAAKKOLA, 2020; STEIN; RAMASESHAN, 2016). Estudos reconhecem a jornada de compra e seus pontos de contato como fatores imprescindíveis na experiência do consumidor (BECKER; JAAKKOLA, 2020; MCCOLL-KENNEDY et al., 2019; XIANG et al., 2016).

O mapeamento de jornada do cliente é uma ferramenta de gerenciamento estratégico cada vez mais popular, elogiada por acadêmicos e profissionais por sua utilidade na compreensão da experiência do cliente de uma organização (ROSENBAUM; OTALORA; RAMÍREZ, 2017; LEMON; VERHOEF, 2016). O processo contempla tudo o que uma pessoa precisa fazer para decidir se vai adquirir determinado produto ou serviço (LEMON; VERHOEF, 2016). Esse quesito é tão importante que um dado da SiriusDecisions indica que em 67\% dos casos a jornada é finalizada antes mesmo de o cliente alcançar a etapa de compra, o que significa que ele desiste de comprar em uma loja e opta pela concorrência (QUER..., 2018).

No contexto acadêmico, o tópico da jornada do cliente é considerado como prioridade de pesquisa em marketing entre 2018 e 2020 (Marketing Science Institute, 2018). Porém, apesar do tópico possuir grande importância, não foram identificados estudos que buscassem compreender a jornada do cliente de um shopping popular. Diante deste contexto, este estudo tem como objetivo geral identificar os pontos de contato do cliente em sua jornada de compra no Pop Center de Porto Alegre. A escolha do objeto foi por conta da sua representatividade dentro do cenário econômico de Porto Alegre, visto que gera 4 mil empregos diretos e indiretos (NETO, 2019). Os resultados deste estudo validam o método de mapeamento da jornada do cliente elaborado por Rosenbaum, Otalora e Ramírez (2017), sendo aplicado no contexto de um shopping popular.

Assim, além dessa Introdução, o artigo está divido em outras 4 seções: a fundamentação teórica do estudo, definindo conceitos de experiência de consumo e da jornada do cliente; o método utilizado; a análise dos dados e os resultados do estudo; as conclusões, discutindo implicações gerenciais, limitações e sugestões de estudos complementares.

\section{Fundamentação Teórica}

Nos últimos anos, vários estudos aprofundaram a discussão e trouxeram importantes contribuições para o entendimento da experiência do consumidor e da jornada do cliente (p.ex., BECKER; JAAKKOLA, 2020; CARÙ; COVA, 2003; LEMON; VERHOEF, 2016; ROSENBAUM; OTALORA; RAMÍREZ, 2017). Esta seção se propõe a discutir a experiência de forma crítica, não somente como uma ação para gerar encantamento nos clientes, mas também como uma ferramenta que necessita ser utilizada como estratégia pelas empresas e marcas para que elas possam continuar em destaque em meio a um cenário acelerado e de constante inovação. 


\subsection{Experiência do consumidor}

A noção de experiência do consumidor foi apresentada aos estudos de consumo e marketing com o artigo seminal de Holbrook e Hirschman (1982). Os autores enfatizam que aspectos experienciais são determinantes ao comportamento do consumo e recomendam uma mudança no marketing, com interações focadas no cliente. A ótica experiencial entende a experiência como um estado subjetivo de consciência, com uma variedade de significados simbólicos, respostas hedônicas, critérios estéticos e fenomenológicos em sua essência (MACHADO, 2018). Percebe-se, então, a experiência de consumo como elemento-chave para entender o comportamento do consumidor (CARÙ; COVA, 2003), o que fez com que a temática atraísse cada vez mais atenção entre profissionais e pesquisadores (BECKER, 2018). A experiência acontece como algo singular com o indivíduo que se engaja com o evento de consumo, seja em um nível intelectual, emocional ou físico (PINE; GILMORE, 1998). Abrahams (1986) relata que cada indivíduo tem sua maneira de ver, sentir e reagir a determinada situação ou estímulo. Portanto, uma experiência é vista como um acontecimento pessoal, e duas pessoas não podem ter a mesma experiência, pois a experiência de consumo deriva da interação entre o evento e o indivíduo (PINE; GILMORE, 1998).

Em geral, acadêmicos e profissionais de mercado concordam que a construção da experiência do cliente é de natureza holística e envolve componentes cognitivos, emocionais, comportamentais, sensoriais e sociais (SCHMITT 1999; VERHOEF et al., 2009). Estudos recentes sustentam que as experiências dos consumidores emergem em sistemas de serviços dinâmicos, envolvendo uma multiplicidade de atores, oferecendo recursos que os consumidores integram às suas experiências (AKAKA; VARGO; SCHAU, 2015; JAAKKOLA; HELKKULA; AARIKKA-STENROOS, 2015).

Portanto, a experiência do cliente considera todas as interações do cliente com a empresa, incluindo fases antes, durante e depois da compra e/ou consumo do produto ou serviço (ROSENBAUM; OTALORA; RAMÍREZ, 2017). Esse amplo entendimento da construção da experiência do cliente explica a alta relevância da perspectiva experiencial. Esse conceito permite a integração e, portanto, o avanço de diversos conceitos de marketing, e fornece às empresas uma abordagem eficaz para adquirir uma compreensão abrangente dos requisitos do cliente ao longo de toda a sua jornada de compra (HOMBURG; JOZIĆ; KUEHNL, 2017; LEMON; VERHOEF, 2016).

\subsection{A Jornada do Consumidor}

O mapeamento da jornada do consumidor é uma representação visual da sequência de eventos por meio dos quais os clientes podem interagir com uma organização de serviços durante todo o processo de compra (DEMMERS et al., 2020; ROSENBAUM; OTALORA; RAMÍREZ, 2017). Esse processo é iterativo e dinâmico, visto que, em cada estágio, os clientes experimentam diversos pontos de contato com a empresa (LEMON; VERHOEF, 2016). Na jornada do cliente, os estudos existentes sugerem que diferentes pontos de contato do cliente podem ser identificados (p.ex., BAXENDALE; MACDONALD; WILSON, 2015; DE HAAN; WIESEL; PAUWELS, 2016).

A jornada do cliente é representada a partir de um eixo horizontal e de um eixo vertical (ROSENBAUM; OTALORA; RAMÍREZ, 2017). Os pontos de contato são geralmente representados horizontalmente nos mapas de jornada do cliente, de acordo com uma linha do 
tempo do processo. Lemon e Verhoef (2016) argumentam que a experiência do cliente pode ser representada em três estágios gerais: pré-compra, compra e pós-compra. O período de pré-compra refere-se à experiência do cliente antes de um serviço real começar. No processo de mapeamento da jornada do consumidor de um shopping, por exemplo, a experiência do cliente antes do serviço pode incluir alguns pontos de contato, como ver anúncios do shopping ou ouvir um anúncio de rádio. O período de compra refere-se aos pontos de contato que os clientes vivenciam durante um serviço real, como entrar no estacionamento do shopping, interagir com funcionários ou visitar lojas. O período pós-compra refere-se à experiência do cliente que ocorre após o serviço real. Os pontos de contato, nesse período, podem incluir um cliente indicando um produto para algum amigo ou familiar, ou recebendo um incentivo para retornar ao shopping (ROSENBAUM; OTALORA; RAMÍREZ, 2017).

Após identificar todos os pontos de contato do cliente nos três períodos, as empresas e os profissionais de marketing devem desenvolver categorias estratégicas ao longo do eixo vertical, que descrevem iniciativas relevantes associadas à cada ponto de contato (ROSENBAUM; OTALORA; RAMÍREZ, 2017). Embora o eixo horizontal no mapeamento da jornada do consumidor seja relativamente fácil de compreender, o desenvolvimento do eixo vertical pode ser significativamente mais complexo. Para um mapa de jornada do cliente obter sucesso, ele depende do eixo vertical.

O eixo vertical é composto por 5 ações gerenciais (ROSENBAUM; OTALORA; RAMÍREZ, 2017):

a) Requisitos do comprador: identificar e relacionar os requisitos do cliente que são necessários no ponto de contato (marketing);

b) Ações dos funcionários: identificar e relacionar as ações dos funcionários do shopping necessárias no ponto de contato para atender aos requisitos do cliente (recursos humanos);

c) Suporte ao funcionário: identificar e relacionar treinamentos, tecnologia da informação, licenças, certificação, ferramentas, materiais, entre outros, que os funcionários precisam ter para atender aos requisitos no ponto de contato (gerenciamento de recursos humanos e operações);

d) Design do varejo: especificar os estímulos ambientais que os clientes devem sentir e não sentir em cada ponto de contato para ajudá-los a julgar a qualidade do serviço (marketing, gerenciamento de operações, engenharia de construção); e

e) Inovação em serviços: pensar em como todos os departamentos podem trabalhar juntos em cada ponto de contato para melhorar a experiência do cliente (todos os departamentos). Considerar eliminar possíveis falhas de serviço e os pontos problemáticos do cliente no ponto de contato.

As 5 ações gerenciais propostas por Rosenbaum, Otalora e Ramírez (2017) são pontos importantes a serem avaliados durante o processo de mapeamento da jornada do cliente no contexto de um shopping popular, visto que o shopping é um local físico composto por diversos varejistas, o que torna ainda mais complexa a análise da jornada do cliente. Utilizando os pontos verticais, juntamente com os horizontais, é possível desenvolver um plano de ação mais assertivo para gerar maior satisfação e engajamento com o cliente. 


\section{Metodologia}

O estudo foi realizado com base no artigo de Rosenbaum, Otalora e Ramírez (2017) com intuito de replicar o estudo no contexto de um Shopping Popular, o Pop Center de Porto Alegre, no Rio Grande do Sul (RS). A escolha do objeto foi por conta da sua representatividade dentro do cenário econômico de Porto Alegre. O Pop Center gera 4 mil empregos diretos e indiretos e, mensalmente, 1,5 milhões de pessoas transitam pelo local, entre consumidores do comércio varejista, do estacionamento, dos restaurantes, da agência bancária e de farmácias presentes no estabelecimento. O shopping tem 10 anos de existência e conta com 800 lojas que ocupam os 20 mil metros quadrados do local (NETO, 2019).

Para o desenvolvimento do eixo horizontal, iniciou-se o processo de mapeamento da jornada do consumidor do Pop Center a partir de uma entrevista com a equipe de gerenciamento do shopping, para identificar os pontos de contato que os clientes podem experienciar durante sua jornada de compra. Os pontos de contato foram categorizados em três períodos: aqueles que ocorrem antes, durante e após o serviço, conforme definição de Lemon e Verhoef (2016). Neste estudo, será utilizada a nomenclatura serviço ao invés de compra, por entender que os indivíduos que responderam ao questionário poderiam ou não estar em período de compras. A entrevista com a equipe de gerenciamento do shopping resultou na identificação de 40 pontos de contato com os clientes, cada um ilustrando um momento em que os clientes têm um ponto de interação com o shopping. Desses, 10 representavam pontos de contato de pré-serviço, 25 referiam-se a pontos de contato de serviço e 5 estavam alinhados com o pós-serviço.

Como discutido anteriormente, a análise da jornada do cliente deve entender e mapear a jornada pela perspectiva do cliente e, portanto, requer a contribuição do cliente (LEMON; VERHOEF, 2016). Por isso, seguindo o protocolo metodológico utilizado por Rosenbaum, Otalora e Ramírez (2017) para desenvolvimento do eixo horizontal, foi realizada uma coleta de dados com clientes via questionários aplicados, seguindo uma amostra por conveniência. $\mathrm{O}$ questionário foi desenvolvido com base nas respostas obtidas durante a entrevista com a equipe de gerenciamento do Pop Center, em que cada ponto de contato identificado pela equipe foi traduzido em uma questão do questionário.

A coleta de dados foi realizada de forma presencial e foram obtidos 100 questionários válidos respondidos por clientes em várias partes do shopping popular. Para análise dos resultados e proposição de ações estratégicas, foram identificados os 10 principais pontos da jornada do ciente, seguindo protocolo de pesquisa de Rosenbaum, Otalora e Ramírez (2017).

\section{Resultados}

Nesta seção, são apresentados os resultados e analisados os 10 principais pontos da jornada do cliente, realizados através do cruzamento do eixo horizontal com o eixo vertical, conforme estudo de Rosenbaum, Otalora e Ramírez (2017).

Os participantes representam uma amostra por conveniência dos clientes do shopping, que se voluntariaram a participar do estudo. Dos entrevistados, 62 eram mulheres e 38 eram homens e suas idades variaram em 13 e 66 anos. Este dado está alinhado com um estudo realizado em 2014 por uma empresa de pesquisa de mercado contratada para identificar o público do Pop Center. Na pesquisa, identificou-se que 59,3\% do público é feminino e 40,7\% do público 
é masculino.

Em relação às cidades de residência dos entrevistados, a que possui maior número de respondentes foi Porto Alegre, com 41\%, seguida de Canoas (10\%), Gravataí (9\%), Esteio (6\%) e Cachoeirinha (5\%). É possível observar que todas as cidades com maior número de entrevistados pertencem à região metropolitana de Porto Alegre (CIDADE-BRASIL, [2019]), o que pode ser justificável pelo fácil acesso ao local. Ainda, em relação à escolaridade dos entrevistados, mais da metade (51\%) dos entrevistados possui Ensino Médio completo. Estes resultados nos mostram que o nível de escolaridade da amostra utilizada está acima da média nacional, que é de $24,3 \%$ (IBGE, 2019).

Durante a pesquisa, foi solicitado, aos participantes, que respondessem um questionário sobre se haviam interagido de cada um dos 40 pontos de contato na atual visita ao local $(0=$ não, $1=\mathrm{sim})$. Com base nas respostas, foram selecionados os 10 principais pontos de contato, apresentados na Tabela 1.

Tabela 1 - Principais pontos de contato identificados pelos consumidores

\begin{tabular}{lc}
\hline \multicolumn{1}{c}{ Ponto de contato } & (\% sim) \\
\hline Período pré-serviço (Antes de você decidir vir até o Pop Center hoje, você...) & 94 \\
1. Visitou o Pop Center alguma vez anteriormente? & 53 \\
2. Falou com outras pessoas sobre o Pop Center? & 34 \\
3.Viu a propaganda na passarela em frente ao Pop Center? & 86 \\
Período durante o serviço (Durante o tempo que você está no Pop Center hoje, você...) & 81 \\
1. Sentiu que está em um ambiente limpo? & 73 \\
2. Fez alguma compra por conta do preço do produto? & 70 \\
3. Se sentiu seguro(a)? & \\
4. Sentiu que está em um ambiente organizado? & 96 \\
Período pós-serviço (Depois de fazer suas compras no Pop Center hoje, você planeja \\
realizar alguma dessas atividades?) \\
1. Retornar ao Pop Center em breve? \\
$\begin{array}{l}\text { 2. Recomendar uma loja localizada no Pop Center para algum familiar ou } \\
\text { amigo? }\end{array}$ \\
$\begin{array}{l}\text { 3. Recomendar a praça de alimentação do Pop Center para algum familiar ou } \\
\text { amigo? }\end{array}$
\end{tabular}

Fonte: Elaborado pelos autores (2020).

\subsection{Pontos de contato antes do serviço}

Os principais pontos de contato do cliente apontados no resultado da pesquisa no período pré-serviço são as visitas anteriores de um cliente ao shopping, conversas sobre o shopping com outras pessoas e experiência com estímulo publicitário na passarela em frente ao Pop Center. O resultado da coleta do período pré-serviço realizada com clientes do Pop Center foi semelhante ao da coleta realizada com clientes do shopping utilizado no artigo referência deste estudo (ROSENBAUM; OTALORA; RAMÍREZ, 2017). Apesar dos dois shoppings estarem em realidades e contextos diferentes - o shopping deste estudo se trata de um shopping popular e o objeto do estudo de Rosenbaum, Otalora e Ramírez (2017) era um dos maiores shoppings mundiais, ao realizar o cruzamento do eixo horizontal com o eixo vertical, sugere-se ações estratégicas adaptadas ao contexto do Pop Center. 
As ações estratégicas são apresentadas no Quadro 1, como resultado do cruzamento do eixo vertical, caracterizado pelas ações gerenciais propostas por Rosenbaum, Otalora e Ramírez (2017) e eixo horizontal, pontos de contato identificados pelos clientes.

Quadro 1 - Mapa da jornada do cliente no período pré-serviço

\begin{tabular}{|c|c|c|c|}
\hline & \multicolumn{3}{|c|}{ Ponto de contato } \\
\hline & $\begin{array}{c}\text { Visita anterior ao Pop } \\
\text { Center }\end{array}$ & $\begin{array}{l}\text { Falou com outras } \\
\text { pessoas sobre o Pop } \\
\text { Center }\end{array}$ & $\begin{array}{l}\text { Viu propaganda do Pop } \\
\text { Center na passarela }\end{array}$ \\
\hline $\begin{array}{l}\text { Requisitos do } \\
\text { cliente }\end{array}$ & $\begin{array}{l}\text { Deseja ter a mesma ou } \\
\text { experiência positiva } \\
\text { semelhante que teve no } \\
\text { passado. }\end{array}$ & $\begin{array}{l}\text { Deseja ter atitude e } \\
\text { satisfação positiva em } \\
\text { relação às compras do } \\
\text { shopping. }\end{array}$ & $\begin{array}{c}\text { Propagandas devem ser } \\
\text { visualmente chamativas } \\
\text { e criativas para atrair sua } \\
\text { atração. }\end{array}$ \\
\hline $\begin{array}{l}\text { Ações dos } \\
\text { funcionários }\end{array}$ & $\begin{array}{l}\text { Nomear funcionários } \\
\text { como embaixadores dos } \\
\text { clientes em mesas de } \\
\text { informações perto de } \\
\text { cada entrada ou saída do } \\
\text { shopping. Garantir que } \\
\text { os clientes do shopping } \\
\text { estejam satisfeitos } \\
\text { durante e após a sua } \\
\text { jornada de compra. }\end{array}$ & $\begin{array}{l}\text { A direção do shopping } \\
\text { deve trabalhar ativamente } \\
\text { com a assessoria de } \\
\text { imprensa para promover } \\
\text { o impacto do shopping } \\
\text { na área. A comunicação } \\
\text { deve enfatizar o impacto } \\
\text { do shopping na mídia } \\
\text { local (número de } \\
\text { empregos, vendas, etc.) }\end{array}$ & $\begin{array}{l}\text { A direção do shopping deve } \\
\text { trabalhar com uma equipe de } \\
\text { comunicação para planejar } \\
\text { a estratégia da comunicação } \\
\text { na área do Pop Center. O } \\
\text { shopping também trabalha } \\
\text { com lojistas de varejo em } \\
\text { oportunidades de publicidade } \\
\text { cooperativa. }\end{array}$ \\
\hline $\begin{array}{l}\text { Suporte ao } \\
\text { funcionário }\end{array}$ & $\begin{array}{c}\text { Embaixadores do } \\
\text { cliente devem receber } \\
\text { treinamento para } \\
\text { atendimento, resolução } \\
\text { de problemas e políticas } \\
\text { do shopping Pop Center. }\end{array}$ & $\begin{array}{l}\text { A assessoria de imprensa } \\
\text { pode criar e distribuir } \\
\text { pacotes de press } \\
\text { releases. O shopping } \\
\text { Pop Center e os lojistas } \\
\text { mais engajados devem } \\
\text { iniciar um trabalho } \\
\text { com organizações } \\
\text { comunitárias. }\end{array}$ & $\begin{array}{l}\text { A direção do shopping pode } \\
\text { trabalhar com terceiros } \\
\text { especializados em publicidade } \\
\text { e propaganda. }\end{array}$ \\
\hline Design & $\begin{array}{l}\text { Podem ser criadas } \\
\text { sinalizações internas que } \\
\text { incentivem os clientes } \\
\text { a fornecerem feedback } \\
\text { aos embaixadores } \\
\text { dos clientes. Os } \\
\text { embaixadores devem ter } \\
\text { um uniforme padrão com } \\
\text { o logotipo do shopping. }\end{array}$ & $\begin{array}{l}\text { Artigos publicados, } \\
\text { anúncios, publicações em } \\
\text { redes sociais, análises de } \\
\text { clientes (Google) devem } \\
\text { ser positivas. }\end{array}$ & $\begin{array}{c}\text { Os clientes do shopping devem } \\
\text { ser capazes de visualizar a } \\
\text { propaganda do Pop Center na } \\
\text { passarela. }\end{array}$ \\
\hline $\begin{array}{l}\text { Inovação em } \\
\text { serviços }\end{array}$ & $\begin{array}{c}\text { O shopping pode } \\
\text { promover sorteios para } \\
\text { incentivar os clientes a } \\
\text { avaliarem o shopping nas } \\
\text { redes sociais. }\end{array}$ & $\begin{array}{l}\text { Contratação de um } \\
\text { profissional para ser } \\
\text { responsável pelas } \\
\text { mídias sociais, e-mail e } \\
\text { marketing móvel e pelo } \\
\text { monitoramento de mídias } \\
\text { sociais com software de } \\
\text { acompanhamento. }\end{array}$ & $\begin{array}{l}\text { Iniciar novos tipos de } \\
\text { publicidade, como painéis } \\
\text { internos no shopping e sacolas } \\
\text { com o logotipo do shopping. }\end{array}$ \\
\hline
\end{tabular}

Fonte: elaborado pelos autores (2020). 
Após perceber a importância dos três pontos de contato pré-serviço apresentados, espera-se que o Pop Center planeje iniciativas estratégicas em cada um e implemente estratégias de inovação de serviço para melhorar a experiência do comprador. Por exemplo, dada a importância da experiência anterior de um cliente em incentivar comportamentos futuros, o Pop Center pode colocar embaixadores de clientes em cada entrada e saída do shopping para incentivar os compradores a fornecer feedback e participar de um sorteio, verificando as mídias sociais ou usando as informações do shopping. Além disso, como a pesquisa mostrou que a maioria dos compradores do Pop Center percebeu a propaganda na passarela na frente do shopping, a direção pode iniciar um trabalho em parceria com uma agência de publicidade para pensar em novas mídias internas. Além disso, as ações estratégias sugeridas não apresentam um custo operacional muito elevado e podem trazer benefícios a médio e longo prazo que justifiquem os investimentos iniciais para o desenvolvimento das ações.

\subsection{Pontos de contato durante o serviço}

Durante o período de serviço, foram identificados quatro principais pontos de contato com o cliente. Esses pontos de contato incluem os clientes do Pop Center comprarem no shopping por conta do preço dos produtos, fatores de design do shopping como limpeza e organização e, também, o fato dos cliente se sentirem seguros dentro do Pop Center - um fator extremamente importante, visto que a localização do shopping é em uma zona de baixa segurança pública. Ao contrário do que aconteceu durante o período pré-serviço, os pontos de contato identificados neste estudo não foram semelhantes aos encontrados no estudo de Rosenbaum, Otalora e Ramírez (2017). A seguir, o Quadro 2 apresenta esses pontos de contato do cliente que ocorrem durante o período de serviço.

Quadro 2 - Mapa da jornada do cliente no período de serviço

\begin{tabular}{|c|c|c|c|c|}
\hline & \multicolumn{4}{|c|}{ Ponto de contato } \\
\hline & Preço do produto & $\begin{array}{c}\text { Ambiente } \\
\text { organizado }\end{array}$ & Ambiente seguro & Ambiente limpo \\
\hline $\begin{array}{l}\text { Requisitos } \\
\text { do cliente do } \\
\text { shopping }\end{array}$ & $\begin{array}{c}\text { Espera encontrar os } \\
\text { melhores preços do } \\
\text { mercado. }\end{array}$ & $\begin{array}{l}\text { Espera encontrar } \\
\text { um ambiente } \\
\text { organizado, } \\
\text { tanto em relação } \\
\text { à organização de } \\
\text { produtos quanto } \\
\text { na organização } \\
\text { das lojas. }\end{array}$ & $\begin{array}{c}\text { Espera se sentir } \\
\text { seguro(a) dentro } \\
\text { do shopping Pop } \\
\text { Center. }\end{array}$ & $\begin{array}{l}\text { Espera encontrar um } \\
\text { ambiente limpo, tanto } \\
\text { na parte das lojas } \\
\text { quanto na praça de } \\
\text { alimentação. }\end{array}$ \\
\hline $\begin{array}{l}\text { Ações dos } \\
\text { funcionários }\end{array}$ & $\begin{array}{l}\text { Funcionários devem } \\
\text { estar cientes dos } \\
\text { preços dos produtos } \\
\text { e ter autonomia para } \\
\text { negociação de acordo } \\
\text { com a margem do } \\
\text { produto. }\end{array}$ & $\begin{array}{l}\text { Os embaixadores } \\
\text { dos clientes } \\
\text { devem realizar } \\
\text { rondas diárias } \\
\text { com a intenção } \\
\text { de verificar a } \\
\text { organização do } \\
\text { shopping. }\end{array}$ & $\begin{array}{l}\text { Seguranças } \\
\text { contratados } \\
\text { devem realizar } \\
\text { rondas diárias } \\
\text { com a intenção } \\
\text { de verificar a } \\
\text { segurança do } \\
\text { shopping. }\end{array}$ & $\begin{array}{l}\text { Os embaixadores } \\
\text { de clientes devem } \\
\text { realizar rondas diárias } \\
\text { com a intenção de } \\
\text { verificar a limpeza do } \\
\text { shopping. Além disso, } \\
\text { deve-se desenvolver } \\
\text { uma comunicação } \\
\text { visual interna com } \\
\text { mensagens para os } \\
\text { clientes manter a } \\
\text { limpeza do local, } \\
\text { jogar lixo no lixo, etc. }\end{array}$ \\
\hline
\end{tabular}




\begin{tabular}{|c|c|c|c|c|}
\hline & \multicolumn{4}{|c|}{ Ponto de contato } \\
\hline & Preço do produto & $\begin{array}{c}\text { Ambiente } \\
\text { organizado }\end{array}$ & Ambiente seguro & Ambiente limpo \\
\hline $\begin{array}{l}\text { Suporte ao } \\
\text { funcionário }\end{array}$ & $\begin{array}{c}\text { O Pop Center } \\
\text { deve fornecer aos } \\
\text { lojistas um curso } \\
\text { com boas práticas } \\
\text { de atendimento ao } \\
\text { cliente. }\end{array}$ & $\begin{array}{l}\text { O Pop Center } \\
\text { deve fornecer } \\
\text { aos lojistas um } \\
\text { curso com boas } \\
\text { práticas de } 5 \mathrm{~S} \text {. }\end{array}$ & $\begin{array}{l}\text { O Pop Center } \\
\text { deve trabalhar } \\
\text { juntamente com } \\
\text { a assessoria } \\
\text { de imprensa } \\
\text { para diminuir } \\
\text { o número de } \\
\text { matérias negativas } \\
\text { em relação à } \\
\text { segurança do } \\
\text { shopping. }\end{array}$ & $\begin{array}{l}\text { O Pop Center deve } \\
\text { fornecer aos lojistas } \\
\text { um curso com } \\
\text { boas práticas de } 5 \mathrm{~S} \\
\text { e um curso para } \\
\text { aprendizado em } \\
\text { relação à reciclagem e } \\
\text { descarte do lixo. }\end{array}$ \\
\hline $\begin{array}{l}\text { Design do } \\
\text { shopping }\end{array}$ & $\begin{array}{l}\text { Devem ser criadas } \\
\text { sinalizações internas } \\
\text { que reiterem o fato de } \\
\text { o preço do produto } \\
\text { ser muito competitivo } \\
\text { para a região. }\end{array}$ & $\begin{array}{c}\text { Devem ser } \\
\text { criadas } \\
\text { sinalizações } \\
\text { internas que } \\
\text { comuniquem } \\
\text { aos clientes a } \\
\text { necessidade } \\
\text { de manter } \\
\text { o ambiente } \\
\text { organizado, } \\
\text { visto que é um } \\
\text { espaço formado } \\
\text { por diversos } \\
\text { comerciantes e } \\
\text { clientes. }\end{array}$ & $\begin{array}{l}\text { Deve ser criada } \\
\text { comunicação } \\
\text { visual interna } \\
\text { comunicando } \\
\text { a segurança do } \\
\text { local (segurança } \\
\text { terceirizada, } \\
\text { câmeras de } \\
\text { vigilância). Além } \\
\text { disso, deve-se } \\
\text { trabalhar para } \\
\text { veicular notícias } \\
\text { positivas nos } \\
\text { veículos de mídia. }\end{array}$ & $\begin{array}{c}\text { Deve-se instalar } \\
\text { lixeiras com } \\
\text { identificação visual } \\
\text { para a separação do } \\
\text { lixo. }\end{array}$ \\
\hline $\begin{array}{l}\text { Inovação em } \\
\text { serviços }\end{array}$ & $\begin{array}{l}\text { Sugere-se a criação } \\
\text { de um aplicativo } \\
\text { para comparação de } \\
\text { preço dos lojistas } \\
\text { com demais lojas da } \\
\text { região. }\end{array}$ & $\begin{array}{c}\text { Sugere-se a } \\
\text { aplicação do } \\
\text { programa 5S. }\end{array}$ & $\begin{array}{c}\text { Sugere-se a } \\
\text { contratação de } \\
\text { mais câmeras } \\
\text { internas e externas } \\
\text { para o shopping. }\end{array}$ & $\begin{array}{c}\text { Sugere-se a } \\
\text { contratação de uma } \\
\text { empresa para realizar } \\
\text { a coleta seletiva para } \\
\text { correta destinação } \\
\text { dos resíduos gerados } \\
\text { dentro do shopping. }\end{array}$ \\
\hline
\end{tabular}

Fonte: Elaborado pelos autores (2020).

A partir dos resultados da pesquisa, sugere-se essas ações para um aprimoramento da experiência do cliente durante o período de serviço dentro do Pop Center. É bastante importante três dos pontos de contato identificados pelos clientes estarem relacionados a limpeza, organização e segurança do local, visto que se trata de um shopping popular. Ainda, algumas das ações estratégicas sugeridas são de fácil implementação, como o exemplo da veiculação de notícias positivas nos veículos de mídia, visto que o Pop Center possui uma assessoria de imprensa e não teria nenhum custo adicional para o desenvolvimento da ação. Já outras ações exigem maiores esforços financeiros, como o desenvolvimento de um aplicativo para a comparação de preços e desenvolvimento de curso de boas práticas com equipe do Pop Center.

Sugere-se, ainda, que as ações estratégicas sejam realizadas por etapas, a partir da avaliação da diretoria a partir de critérios de importância. Após análise e sugestão das ações para o período de serviço, a seguir são indicadas ações a serem executadas durante o período pós-serviço. 


\subsection{Pontos de contato após o serviço}

No período pós-serviço, foram identificados, como pontos de contato principais, a recomendação de uma loja, a recomendação da praça de alimentação e o planejamento de um retorno breve para o Pop Center. Dois dos três pontos de contato principais acabaram sendo os mesmos identificados pelo estudo de Rosenbaum, Otalora e Ramírez (2017). Sendo assim, ao realizar o cruzamento dos eixos horizontal e vertical, algumas das ações sugeridas são as mesmas já implementadas no shopping que foi objeto do estudo. Novamente, o motivo da sugestão de algumas ações serem as mesmas é por conta de, mesmo em contextos diferentes, são ações simples e de fácil execução para a realidade do Pop Center. O Quadro 4 apresenta os três principais pontos de contato que acontecem depois que um cliente sai do shopping.

Quadro 3 - Mapa de jornada do cliente no período pós-serviço

\begin{tabular}{|c|c|c|c|}
\hline & \multicolumn{3}{|c|}{ Ponto de contato } \\
\hline & $\begin{array}{c}\text { Recomendar uma loja } \\
\text { para um amigo ou } \\
\text { familiar }\end{array}$ & $\begin{array}{l}\text { Recomendar a praça de } \\
\text { alimentação para um } \\
\text { amigo ou familiar }\end{array}$ & $\begin{array}{c}\text { Planejar retornar ao Pop } \\
\text { Center }\end{array}$ \\
\hline $\begin{array}{l}\text { Requisitos } \\
\text { do cliente do } \\
\text { shopping }\end{array}$ & $\begin{array}{l}\text { Ter atitude e avaliação } \\
\text { positivas em relação aos } \\
\text { lojistas do Pop Center. }\end{array}$ & $\begin{array}{l}\text { Ter atitude e avaliação } \\
\text { positivas em relação à } \\
\text { praça de alimentação do } \\
\text { Pop Center. }\end{array}$ & $\begin{array}{l}\text { Os compradores do } \\
\text { shopping precisam } \\
\text { de razões (produtos, } \\
\text { serviços, informações, } \\
\text { entretenimento) para } \\
\text { retornar. }\end{array}$ \\
\hline $\begin{array}{l}\text { Ações dos } \\
\text { funcionários }\end{array}$ & $\begin{array}{c}\text { Posicionar os } \\
\text { embaixadores dos } \\
\text { clientes nas centrais de } \\
\text { atendimento próximas } \\
\text { às entradas e saídas para } \\
\text { incentivar o feedback dos } \\
\text { clientes. Também deve } \\
\text { incentivar os lojistas do } \\
\text { shopping a desenvolver } \\
\text { uma a política de } \\
\text { devolução do produto. }\end{array}$ & $\begin{array}{l}\text { Posicionar os embaixadores } \\
\text { dos clientes nas centrais } \\
\text { de atendimento próximas } \\
\text { às entradas e saídas para } \\
\text { incentivar o feedback } \\
\text { dos clientes. Também } \\
\text { incentivar os lojistas do } \\
\text { shopping a desenvolver um } \\
\text { cartão fidelidade. }\end{array}$ & $\begin{array}{l}\text { Planejar estratégias de } \\
\text { comunicação dentro do } \\
\text { Pop Center para que os } \\
\text { clientes recebam em } \\
\text { tempo real as atividades } \\
\text { que acontecem dentro do } \\
\text { shopping, como promoções } \\
\text { das lojas e atividades de } \\
\text { entretenimento. }\end{array}$ \\
\hline $\begin{array}{l}\text { Suporte ao } \\
\text { funcionário }\end{array}$ & $\begin{array}{l}\text { Dispor de profissional } \\
\text { responsável por toda a } \\
\text { comunicação online pós- } \\
\text { serviço com os clientes do } \\
\text { shopping. }\end{array}$ & $\begin{array}{l}\text { Dispor de profissional } \\
\text { responsável por toda a } \\
\text { comunicação online pós- } \\
\text { serviço com os clientes da } \\
\text { praça de alimentação. }\end{array}$ & $\begin{array}{l}\text { Direção e funcionários } \\
\text { do shopping devem ter } \\
\text { conhecimento de básico de } \\
\text { marketing. }\end{array}$ \\
\hline $\begin{array}{l}\text { Design do } \\
\text { shopping }\end{array}$ & $\begin{array}{l}\text { Os clientes do shopping } \\
\text { com acesso à internet } \\
\text { responderão às iniciativas } \\
\text { online que incentivem o } \\
\text { diálogo entre os clientes do } \\
\text { shopping. }\end{array}$ & $\begin{array}{l}\text { Os clientes do shopping } \\
\text { com acesso à internet } \\
\text { responderão às iniciativas } \\
\text { online que incentivem o } \\
\text { diálogo entre os clientes da } \\
\text { praça de alimentação. }\end{array}$ & $\begin{array}{l}\text { Os clientes irão reagir à } \\
\text { interface de aplicativos } \\
\text { móveis (caso o Pop Center } \\
\text { crie o seu), facilidade } \\
\text { de identificação de } \\
\text { comunicação interna do } \\
\text { shopping e apelo geral ao } \\
\text { design. }\end{array}$ \\
\hline $\begin{array}{l}\text { Inovação em } \\
\text { serviços }\end{array}$ & $\begin{array}{l}\text { Lançar iniciativas online } \\
\text { que incentivem os clientes } \\
\text { a divulgar feedback } \\
\text { positivo de boca em boca: } \\
\text { blog, Facebook, etc., e } \\
\text { iniciativas offline, como } \\
\text { programas de indicação. }\end{array}$ & $\begin{array}{l}\text { Lançar iniciativas online } \\
\text { que incentivem os clientes } \\
\text { a divulgar feedback } \\
\text { positivo de boca em boca: } \\
\text { blog, Facebook, etc., e } \\
\text { iniciativas offline, como } \\
\text { programas de indicação. }\end{array}$ & $\begin{array}{l}\text { Desenvolvimento } \\
\text { de aplicativo móvel } \\
\text { para smartphone e } \\
\text { desenvolvimento de } \\
\text { comunicações internas } \\
\text { que permitam ao cliente } \\
\text { interagir com o lojista. }\end{array}$ \\
\hline
\end{tabular}

Fonte: Elaborado pelos autores (2020). 
De maneira geral, sugere-se que o Pop Center incentive seus clientes a compartilhar experiências e recomendações, tanto em ambientes online, como Facebook e Google, como em ambientes offline, por meio de boca a boca positivo. É importante o incentivo ao compartilhamento de recomendações em ambientes digitais, para verificar se é uma prática já realizada pelos clientes de forma orgânica (sem incentivo). Atualmente, o Pop Center conta com nota 4 (de 5) no Google (nota atribuída por 29.771 pessoas ${ }^{1}$ ). O incentivo de divulgação boca a boca (para amigos e familiares) é imprescindível, visto que um dos pontos de contato encontrados no período pós-serviço é o de recomendar uma loja para alguém. Além disso, sugere-se um início de interação do shopping com as redes sociais e as tecnologias, como a criação de um aplicativo.

\section{Conclusões}

Este estudo foi desenvolvido com base no estudo de Rosenbaum, Otalora e Ramírez (2017) e aplicado em um contexto de um shopping popular. O objetivo do estudo foi identificar os pontos de contato do cliente em sua jornada de compra no Pop Center de Porto Alegre. As análises realizadas proporcionam subsídios para o Pop Center desenvolver ações que visam o aprimoramento da jornada do cliente. Os pontos de contato identificados fornecem insights relevantes para formulação de estratégias de marketing experiencial.

Por meio das análises realizadas, conclui-se que o desenvolvimento do cruzamento entre os eixos vertical e horizontal da jornada do cliente é fundamental para que se tenha um apropriado mapeamento de sua jornada. O método elaborado por Rosenbaum, Otalora e Ramírez (2017) que une os pontos de contato listados pelos clientes (eixo horizontal) com práticas gerenciais aplicáveis (eixo vertical) apresenta o que os clientes realmente fazem durante sua jornada de consumo, ao invés do que a empresa apenas imagina que eles fazem. A partir deste estudo, Pop Center tem um mapeamento da jornada do cliente que pode gerar resultados efetivos para o shopping.

O estudo traz interessantes contribuições a literatura: primeiro, reforça a importância do entendimento da experiência do cliente em situações de compra e consumo de produtos e serviços. Ao relacionar o eixo horizontal com o eixo vertical, conforme proposto por Rosenbaum, Otalora e Ramírez (2017), é possível fazer a sugestão de ações estratégicas que impactem de forma bastante significativa a experiência do cliente. A experiência do cliente é central para a competitividade no cenário do varejo (BECKER; JAAKKOLA, 2020) e desenvolver ações estratégias focadas no cliente são fundamentais para manutenção de uma boa posição no mercado.

Segundo, aprofunda a discussão sobre a jornada do cliente, antes, durante e depois da compra. Como o próprio nome já diz, a jornada do consumidor trata-se do caminho que o consumidor percorre durante todo o processo de consumo, por meio do qual o mesmo vai experimentando elementos dos produtos e serviços oferecidos direta ou indiretamente pelas organizações (LEMON; VERHOEF, 2016). Assim, não somente os pontos de contato durante a compra são importantes, mas sim os pontos de contato que constituem toda a jornada do cliente, fazendo com que o cliente tenha uma experiência positiva durante todo o processo de consumo.

Terceiro, valida o método de mapeamento da jornada do cliente elaborado por Rosenbaum, Otalora e Ramírez (2017), aplicando-o no contexto de shopping popular. Apesar de grande aumento nas publicações acadêmicas relacionadas a experiência e jornada do cliente (BECKER; JAAKKOLA, 2020), carecem pesquisas no contexto dos pequenos varejistas e 1 Acesso em julho de 2020 
shoppings populares. Ainda, entende-se como importante a validação do método elaborado por Rosenbaum, Otalora e Ramírez (2017), visto que um maior número de varejistas pode utilizar o método para elaboração de ações estratégias para seus negócios.

Como implicações gerenciais, o mapeamento da jornada do cliente do oferece informações valiosas para a construção de suas estratégias de marketing. As ações propostas tendem a melhorar a experiência dos clientes em cada ponto de contato identificado como principal. Além do contexto de shopping popular, os resultados do estudo e as estratégias propostas podem servir como apoio no desenvolvimento do planejamento de marketing de outros shoppings e grandes varejos.

O presente estudo possui limitações a serem abordadas. Primeiro, os resultados deste artigo são fundamentados em um único contexto, o de shopping center popular. Portanto, os resultados apresentados não podem ser generalizados para outras circunstâncias. Segundo, a coleta do estudo ficou restrita a apenas um shopping center, sendo interessante um número maior de shoppings para propostas de estudos futuros.

Sugere-se que pesquisas futuras associem a aplicação do mapeamento da jornada do cliente a indicadores de resultado do varejista, além de acompanhamento longitudinal da eficácia e do impacto das ações. Além disso, recomenda-se que estudos semelhantes sejam feitos com os varejistas do shopping, para entender a jornada do cliente de cada loja e comparar com a jornada do cliente do shopping. Por fim, recomenda-se uma análise mais abrangente, realizando um estudo qualitativo para entender com maior profundidade a jornada do cliente e sua relação com cada ponto de contato.

Como considerações finais, pontua-se que, pela perspectiva do marketing, os clientes desejam mais do que apenas a compra e o consumo de produtos e serviços. Em vez disso, eles buscam momentos que criam experiência positivas durante a compra (BECKER; JAAKKOLA, 2020; WALLS et al., 2011). Por isso, empresas e marcas necessitam criar jornadas de consumo e compra que façam com que o cliente tenha experiências positivas.

\section{Referências}

ABRAHAMS, R. D. Ordinary and extraordinary experience. The Anthropology of Experience, p. 45-72, 1986.

AKAKA, M. A.; VARGO, S. L.; SCHAU, H.J. The context of experience. Journal of Service Management, v. 26, n. 2, p. 206-223, 2015.

BAXENDALE, S.; MACDONALD, E. K.; WILSON, H. N. The impact of different touchpoints on brand consideration. Journal of Retailing, v. 91, n. 2, p. 235-253, 2015.

BECKER, L.; JAAKKOLA, E. Customer experience: fundamental premises and implications for research. Journal of the Academy of Marketing Science, p. 1-19, 2020.

BECKER, L. Methodological proposals for the study of consumer experience. Qualitative Market Research: An International Journal, v. 21, n. 4, p. 465-490, 2018. 
CARÙ, A.; COVA, B. Revisiting consumption experience: A more humble but complete view of the concept. Marketing Theory, v. 3, n. 2, p. 267-286, 2003.

CIDADE-BRASIL. Região Metropolitana de Porto Alegre. [s.l.:s.n., 2019]. Disponível em: cidade-brasil.com.br/regiao-metropolitana-de-porto-alegre.html. Aceso em: 17 nov. 2019.

DE HAAN, E.; WIESEL, T.; PAUWELS, K. The effectiveness of different forms of online advertising for purchase conversion in a multiple-channel attribution framework. International Journal of Research in Marketing, v. 33, n. 3, p. 491-507, 2016.

DEMMERS, Joris; WELTEVREDEN, Jesse WJ; VAN DOLEN, Willemijn M. Consumer Engagement with Brand Posts on Social Media in Consecutive Stages of the Customer Journey. International Journal of Electronic Commerce, v. 24, n. 1, p. 53-77, 2020.

FIORE, A. M. et al. Experience economy strategies: Adding value to small rural businesses. Journal of Extension, v. 45, n. 2, p. 1-13, 2007.

HOLBROOK, M. B.; HIRSCHMAN, E. C. The experiential aspects of consumption: Consumer fantasies, feelings, and fun. Journal of Consumer Research, v. 9, n. 2, p. 132-140, 1982.

HOMBURG, C.; JOZIĆ, D.; KUEHNL, C. Customer experience management: Toward implementing an evolving marketing concept. Journal of the Academy of Marketing Science, v. 45, n. 3 , p. $377-401,2017$.

IBGE. Pesquisa nacional por amostra de domicílios contínua trimestral. Brasília: IBGE, 2019. Disponível em: https://sidra.ibge.gov.br/tabela/5919\#resultado. Acesso em: 18 nov. 2019.

JAAKKOLA, E.; HELKKULA, A.; AARIKKA-STENROOS, L. Service experience cocreation: Conceptualization, implications, and future research directions. Journal of Service Management, v. 26, n. 2, p. 182-205, 2015.

LEMON, K. N.; VERHOEF, P. C. Understanding customer experience throughout the customer journey. Journal of Marketing, v. 80, n. 6, p. 69-96, 2016.

MACHADO, M. A. D. Possuir ou experienciar?: Entendendo as relações entre o materialismo e o experiencialismo ao longo do processo de consumo de uma experiência. 2018. Dissertação (Mestrado em Administração) - Escola de Negócios, Pontifícia Universidade Católica do Rio Grande do Sul, Porto Alegre, 2018.

MARKETING SCIENCE INSTITUTE. Research Priorities. 10 jun 2020. Disponível em: https://www.msi.org/research/

MCCOLL-KENNEDY, J. R.; ZAKI, M; LEMON, K. N., URMETZER, F.; NEELY, A. Gaining customer experience insights that matter. Journal of Service Research, v. 22, n. 1, p. 8-26, 2019. 
NETO, A. 10 anos do Pop Center: Conheça histórias de quem trabalha no shopping popular da Capital. Zero Hora, 26 jan. 2019. Disponível em: https://gauchazh.clicrbs.com.br/porto-alegre/ noticia/2019/01/10-anos-do-pop-center-conheca-historias-de-quem-trabalha-no-shoppingpopular-da-capital-cjrcg2ogv00ne01q9c44d5svx.html. Acesso em: 17 nov. 2019.

PINE, B. J.; GILMORE, J. H. Welcome to the experience economy. Harvard Business Review, v. 76, p. 97-105, 1998.

QUER entender a jornada do consumidor? Este guia vai ajudar você! TOTVS, 30 nov. 2018. Disponível em: https://www.totvs.com/blog/jornada-do-consumidor/. Acesso em: 17 nov. 2019.

ROSENBAUM, M. S.; OTALORA, M. L.; RAMÍREZ, G. C. How to create a realistic customer journey map. Business Horizons, v. 60, n. 1, p. 143-150, 2017.

SCHMITT, B. H. Experiential marketing: How to get customers to sense, feel, think, act, and relate to your company and brands. New York: Free Press, 1999.

STEIN, A.; RAMASESHAN, B. Towards the identification of customer experience touch point elements. Journal of Retailing and Consumer Services, v. 30, p. 8-19, 2016.

VERHOEF, P. C. et al. Customer experience creation: Determinants, dynamics and management strategies. Journal of Retailing, v. 85, n. 1, p. 31-41, 2009.

WALLS, A. R. et al. An epistemological view of consumer experiences. International Journal of Hospitality Management, v. 30, n. 1, p. 10-21, 2011.

XIANG, Z. et al. What can big data and text analytics tell us about hotel guest experience and satisfaction?. International Journal of Hospitality Management, v. 44, p. 120-130, 2015. 